\title{
An Experimental Study of Self-Compacting Concrete Made with Filler from Construction and Demolition Waste
}

\author{
Mônica Batista Leite ${ }^{1 *}$, Marcela Crusoé Figueiredo² \\ ${ }^{1}$ Civil and Environmental Engineering Graduate Program, Department of Technology, State University of Feira de Santana, \\ Feira de Santana, Brazil \\ ${ }^{2}$ UNIFACS, Feira de Santana, Brazil \\ Email: ^mleite.uefs@gmail.com
}

How to cite this paper: Leite, M.B. and Figueiredo, M.C. (2020) An Experimental Study of Self-Compacting Concrete Made with Filler from Construction and Demolition Waste. Open Journal of Civil Engineering, 10, 364-384.

https://doi.org/10.4236/ojce.2020.104028

Received: November 9, 2020

Accepted: December 15, 2020

Published: December 18, 2020

Copyright $\odot 2020$ by author(s) and Scientific Research Publishing Inc. This work is licensed under the Creative Commons Attribution International License (CC BY 4.0).

http://creativecommons.org/licenses/by/4.0/

\section{(c) (i) Open Access}

\begin{abstract}
This study evaluated the influence of the Portland cement replacement by 0 , $5 \%, 10 \%, 15 \%$ and $20 \%$ of Construction and Demolition Waste (CDW) filler contents in the production of self-compacting concrete (SCC). The SCC mixtures were evaluated on fresh state by slump flow, J-ring, resistance of segregation, specific gravity, and on hardened state by compressive and splitting tensile strength, specific gravity, air voids and absorption rate. The results indicated that all SCC produced with CDW filler met the limits established at any level of substitution without changes of the w/c ratio or superplasticizer content. It was possible to verify that the presence of CDW filler, in substitution of cement, by volume, improves the resistance to segregation and up to $5 \%$ of CDW filler decreases the loss of fluidity with time as compared to reference. It was found that all SCC mixtures, at 28 days, had the average compressive strength above $50 \mathrm{MPa}$, without showing significant loss with up to $20 \%$ of CDW filler. For splitting tensile strength, SCC recycled mixtures reached up to $92.5 \%$ of the SCC used as reference. Absorption rate and air voids index of SCC recycled mixtures had a maximum increase of $1.60 \%$ Compared to the reference one. So, it is possible to conclude that the use of the CDW filler up to $20 \%$ in substitution of cement, by volume, is feasible for SCC production.
\end{abstract}

\section{Keywords}

Self-Compacting Concrete, Construction and Demolition Waste, Filler, Mineral Admixtures, Slump Flow

\section{Introduction}

The construction industry, as an economic sector, is one of the largest consum- 
ers of natural raw materials, as well as a large generator of solid waste. Estimates indicate that the construction industry currently consumes about $25 \%$ of what is extracted from wood; $40 \%$ of stone, sand and gravel; $16 \%$ of water and generates $50 \%$ of global production of greenhouse gases and acid rain agents and generates a total of about $50 \%$ of solid waste [1] [2].

In Brazil, the Brazilian Association of Public Cleaning and Special Remediation Companies [3] quantified the panorama of Urban Solid Waste (USW) generated and found that $214,868 \mathrm{t} /$ day of USW had been generated in 2017. Of these, 196,050 t/day were collected, of which 123,421 t/day correspond to Construction and Demolition Waste (CDW). Approximately 62.95\% of the USW collected daily in 2017 in Brazil are represented by CDW. In view of the significant generation of CDW and the adoption of Brazilian laws, such as National Council of Environment (CONAMA) Resolution No.307 [4], the National Environmental Council and Federal Law No. 12,305 [5], which require their reduction and recycling applications for this material were sought.

The CDW has often been used instead of the natural fine and/or coarse aggregate in concrete production. Several studies have been carried out applying CDW in conventional concretes (CC): Etxeberria et al. [6] and Richardson et al. [7] replaced the natural coarse aggregate (NCA) with the recycled coarse aggregate (RCA); Leite et al. [8] and Carneiro et al. [9] replaced both the NCA and the natural fine aggregate (NFA) by the recycled aggregates (RA); Leite e Santana [10] and Cartuxo et al. [11] replaced the NFA by recycled fine aggregate (RFA) in order to evaluate the behavior and feasibility of the use of CDW for the production of conventional concrete.

In the studies in which the recycled aggregate was applied, it was observed that some characteristics that differ from the natural aggregates such as heterogeneous composition, high porosity, high fines content, irregular grain shape and rough texture [12] [13]. In the case of high fines, these materials are used as a composition of the fine aggregate [9] [14] and analyzed as part of the aggregate, bringing some complications to the production and properties of the concretes or mortars obtained. When the fines are not used as composition of the FRA they are discarded [15], which environmentally is not an adequate solution, since the volume of this fraction is usually high. Although the characteristics of the AR are different from the natural aggregates (NA), the use of RA in the construction industry has proved feasible, since it reduces CDW storage areas and minimizes costs with the obtaining and commercialization of new aggregates [13].

In addition to the study of the use of recycled aggregates in conventional concrete, it is interesting to evaluate them in other types of concrete and expand the CDW application. Self-compacting concrete (SCC) appears as one more option for the use of alternative materials, since this concrete uses the same raw materials of the CC, but with greater amounts of fines [16].

Concrete to be defined as SCC must simultaneously exhibit three properties in 
the fresh state: fluidity, which is the filling capacity of all void spaces; passing ability, which is the ability of concrete to pass through any obstacles without obstruction; and segregation resistance, which is the ability of the concrete to remain homogeneous during mixing, transport, launch and finishing, without segregation according to NBR 15823-1 [17]. In the hardened state, this concrete needs to meet the same requirements of strength and durability of conventional concretes [16] [18]. Tutikian and Dal Molin [18] guarantee that one of the advantages of using SCC is the use of high levels of industrial waste, which results in a significant environmental contribution. However, in the studies carried out in SCC containing CDW, it was observed that this residue is more commonly used as fine and/or coarse aggregate [19] [20] [21] [22] [23]. CDW is rarely used as a filler, although for the production of the CDW aggregate a large volume of fines is generated and the produced RFA also has a high content of fines in their composition [24]. The use of CDW as a filler would also be an interesting alternative for the SCC, since this type of concrete uses a high content of fines. When the CDW is used as filler in the SCC, as in Perius [25], there is no clear explanation about the influence of this residue on the SCC, how it impacts the properties of the SCC, or what are the best ranges of fines of CDW to be used. Thus, in order to increase the knowledge about the use of CDW filler in cement-based materials, and also to offer another destination option for this material, this work will evaluate the influence of the use of different CDW filler contents in the production of SCC. SCC will be produced, replacing the cement by $0 \%, 5 \%, 10 \%$, $15 \%$ and $20 \%$ of CDW filler content evaluating its properties in fresh and hardened state.

\section{Experimental Program}

\subsection{Materials}

The cement used for the SCC production was High Early Strength Portland cement, which can contain up to $5 \%$ of limestone. The cement had a specific gravity of $3.06 \mathrm{~g} / \mathrm{cm}^{3}$. The mineral addition used was all fine material of CDW (mortar filler) obtained by manual sieving, which passed through the $75 \mu \mathrm{m}$ sieve. This material was obtained by crushing the mortar residue from several demolition sites and clandestine disposal points in the city of Feira de Santana/BA, Brazil, which underwent a gravimetric analysis to separate the inert phases (concrete, mortar, ceramic, natural stones, among others), and removal of impurities. The CDW filler had a specific gravity of $2.46 \mathrm{~g} / \mathrm{cm}^{3}$ and its chemical composition is shown in Table 1 and the grain size curve of the CDW filler and the Portland cement used in this study is presented in Figure 1.

The natural fine aggregates used were a fine quartz sand (FS), with a maximum dimension size of $0.6 \mathrm{~mm}$, fineness modulus of 1.50; specific gravity of $2.62 \mathrm{~g} / \mathrm{cm}^{3}$ and bulk density of $1.48 \mathrm{~g} / \mathrm{cm}^{3}$ and medium quartz sand (MS), with a maximum dimension size of $2.4 \mathrm{~mm}$, fineness modulus of 2.86; specific gravity of $2.57 \mathrm{~g} / \mathrm{cm}^{3}$ and bulk density of $1.42 \mathrm{~g} / \mathrm{cm}^{3}$. The natural coarse aggregates were 
Table 1. Chemical composition of CDW filler.

\begin{tabular}{cccccccccccc}
\hline Oxide & $\mathrm{SiO}_{2}$ & $\mathrm{CaO}$ & $\mathrm{Al}_{2} \mathrm{O}_{3}$ & $\mathrm{Fe}_{2} \mathrm{O}_{3}$ & $\mathrm{TiO}_{2}$ & $\mathrm{MgO}$ & $\mathrm{SO}_{3}$ & $\mathrm{~K}_{2} \mathrm{O}$ & $\mathrm{ZrO}_{2}$ & Other & $\mathrm{LI}^{\mathrm{a}}$ \\
\hline Content (\%) & 47.5 & 19.5 & 9.4 & 3.4 & 2.4 & 1.8 & 0.8 & 0.5 & 0.5 & 0.3 & 14.0 \\
\hline a. LI-loss on ignition. & & & & & & & & & &
\end{tabular}

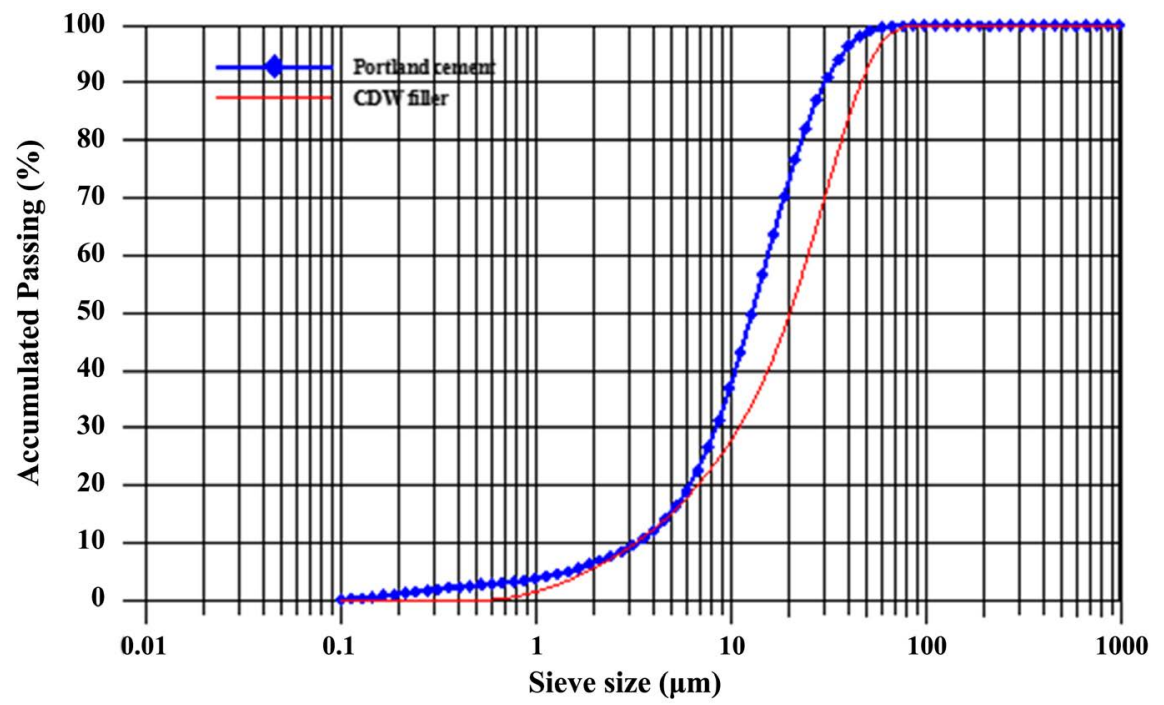

Figure 1. Grading curve analysis of CDW filler and Portland cement.

granitic in origin with a maximum dimension size of $19 \mathrm{~mm}$ (NCA2) and 9.5 $\mathrm{mm}$ (NCA1). The NCA2 presented a fineness modulus of $6.68,2.76 \mathrm{~g} / \mathrm{cm}^{3}$ of specific gravity and bulk density of $1.50 \mathrm{~g} / \mathrm{cm}^{3}$. The NCA1 presented a fineness modulus of $4.28,2.73 \mathrm{~g} / \mathrm{cm}^{3}$ of specific gravity and bulk density of $1.40 \mathrm{~g} / \mathrm{cm}^{3}$.

A third-generation superplasticizer based on polycarboxylate, MasterGlenium ${ }^{\circledR}$ SCC 160 , manufactured by BASF with a specific gravity of $1.07 \mathrm{~g} / \mathrm{cm}^{3}$ and $42 \%$ of solids content was used for the production of the SCC. The recommended dosage of the superplasticizer (SP) is $0.2 \%$ to $1.2 \%$ relative to the weight of the binder.

\subsection{Mix Design and Test Procedure}

The SCC mix design was established according to Gomes [26]. It is an experimental procedure to obtain self-compacting concrete of high performance that meets a minimum compressive strength of at least $50 \mathrm{MPa}$ at 7 days. Once the materials have been chosen, the proposed method separately optimizes the composition of the cement paste so as to obtain the desired viscosity and fluidity, and the aggregate granular skeleton, which guarantees the properties of the SCC in the hardened state. At the end, the lowest void index found was $31.33 \%$ and the bulk density was $1.84 \mathrm{~g} / \mathrm{cm}^{3}$.

For the SCC-R, the following criteria were used: maximum cement paste volume limit of $40 \%$, according to Gomes [26]. As far as fluidity is concerned, the result of the flow test found must be between $660 \mathrm{~mm}$ and $750 \mathrm{~mm}$, as this is the 
adequate spread for most applications, besides being a parameter that is easier to control the resistance of segregation [17] [27] [28]. In what concerns the passing ability, the mixtures should also meet the limits defined by NBR 15823-3 [28], where the difference between the flow obtained with and without the use of the J ring must be at least 0 and at most $50 \mathrm{~mm}$.

The mix proportions for SCC-R production were defined after adjustments in pulp volume, w/c ratio and SP content (Table 2). The mixtures were evaluated in the fresh state for flowability using the flow test [27], plastic viscosity by T500 [27] passing ability using the J-ring [28], resistance to segregation that was evaluated by the visual stability index - VSI [27] and by the sieve method [29] and the specific gravity that was defined by the gravimetric method [30]. In the hardened state, it was evaluated axial compressive strength [31] and splitting tensile strength [32], at 7 and 28 days, and specific gravity, water absorption and void index [33].

\section{Analysis and Discussion of Results}

\subsection{SCC-R in a Fresh State}

Table 3 shows the results of the tests performed on fresh Recycled Self-Compacting Concrete (SCC-R) mixtures. The flow results obtained for the SCC-R mixtures with different filler contents at time 0 (zero) minutes indicate that the mixtures up to the $10 \%$ of CDW filler achieved compatible flow with the SCC of reference (SCC-Ref). For the mixtures 15\%CDW and 20\%CDW there were larger flow reductions of $6 \%$ and $8 \%$, respectively. It can be seen that the addition of the CDW filler, in the case of the 0 min time, did not affect the spreading of the

Table 2. Proportions and consumption of the materials used in the SCC-Ref and SCC-R for $1 \mathrm{~m}^{3}$ of concrete.

\begin{tabular}{cccccccccccc}
\hline $\begin{array}{c}\text { Proportion/ } \\
\text { Consumption }\end{array}$ & Mixtures & w/c & C & $\begin{array}{c}\text { CDW } \\
\text { Filler }\end{array}$ & FS & MS & NCA1 NCA2 & water & $\%$ SP \\
\hline Proportion $(\mathrm{kg} / \mathrm{kg})$ & REF & 0.42 & 1.00 & 0.00 & 0.67 & 1.34 & 0.27 & 1.14 & - & 0.62 \\
Consumption $(\mathrm{kg})$ & REF & 0.42 & 493 & 0 & 332 & 659 & 135 & 563 & 205 & 3.05 \\
Proportion $(\mathrm{kg} / \mathrm{kg})$ & $5 \% \mathrm{CDW}$ & 0.42 & 0.95 & 0.05 & 0.66 & 1.31 & 0.27 & 1.12 & - & 0.62 \\
Consumption $(\mathrm{kg})$ & $5 \% \mathrm{CDW}$ & 0.42 & 475 & 24 & 329 & 652 & 134 & 558 & 208 & 3.09 \\
Proportion $(\mathrm{kg} / \mathrm{kg})$ & $10 \% \mathrm{CDW}$ & 0.42 & 0.91 & 0.09 & 0.65 & 1.28 & 0.26 & 1.10 & - & 0.62 \\
Consumption $(\mathrm{kg})$ & $10 \% \mathrm{CDW}$ & 0.42 & 458 & 46 & 325 & 646 & 133 & 552 & 210 & 3.13 \\
Proportion $(\mathrm{kg} / \mathrm{kg})$ & $15 \% \mathrm{CDW}$ & 0.42 & 0.87 & 0.13 & 0.63 & 1.26 & 0.26 & 1.07 & - & 0.62 \\
Consumption $(\mathrm{kg})$ & $15 \% \mathrm{CDW}$ & 0.42 & 443 & 66 & 323 & 640 & 131 & 547 & 212 & 3.16 \\
Proportion $(\mathrm{kg} / \mathrm{kg})$ & $20 \% \mathrm{CDW}$ & 0.42 & 0.83 & 0.17 & 0.62 & 1.23 & 0.25 & 1.06 & - & 0.62 \\
Consumption $(\mathrm{kg})$ & $20 \% \mathrm{CDW}$ & 0.42 & 429 & 86 & 320 & 635 & 130 & 543 & 214 & 3.19 \\
\hline
\end{tabular}

Note: Ref-_reference; w/c-water/cement ratio; C-Cement; CDW-filler of CDW; FS-natural fine aggregate; MS-natural medium aggregate; NCA1—natural coarse aggregate $9.5 \mathrm{~mm}$; NCA2—natural coarse aggregate $19.00 \mathrm{~mm}$. 
Table 3. Fresh properties of SCC-R mixtures.

\begin{tabular}{ccccccc}
\hline \multirow{2}{*}{ Mixtures } & \multicolumn{5}{c}{ Description } \\
\cline { 2 - 7 } & $\begin{array}{c}\text { Slump-flow } \\
(\mathrm{mm})\end{array}$ & $\begin{array}{c}\text { Slump-flow } \\
\text { time }\left(\mathrm{t}_{500}\right)(\mathrm{s})\end{array}$ & $\begin{array}{c}\text { Visual stability } \\
\text { index (VSI) }\end{array}$ & J-Ring $^{\mathrm{a}}$ & $\begin{array}{c}\text { Sieve segregation } \\
(\%)\end{array}$ & $\begin{array}{c}\text { Density } \\
\left(\mathrm{kg} / \mathrm{m}^{3}\right)\end{array}$ \\
\hline REF & 750 & 0.40 & 0 & 10 & 15 & 2415 \\
$5 \% \mathrm{CDW}$ & 740 & 0.45 & 0 & 10 & 15 & 2394 \\
$10 \% \mathrm{CDW}$ & 750 & 0.92 & 0 & 35 & 12 & 2381 \\
$15 \% \mathrm{CDW}$ & 705 & 1.38 & 0 & 0 & 14 & 2356 \\
$20 \% \mathrm{CDW}$ & 690 & 1.83 & 0 & 20 & 8 & 2338 \\
\hline
\end{tabular}

a. instant 0 (zero) minutes.

concretes because all the mixtures were in the SF 2 spreading class, these concretes could be applied in most structures such as walls, columns, beams and slabs, according to NBR 15823-2 [27].

Checking the results of Figure 2, it is noticed a decrease of the flow over time. It is observed that, for the $15 \mathrm{~min}$ instant, the SCC-R mixtures obtained lower losses when compared to the SCC-Ref. At the instant 15 min the lowest losses were presented for the $5 \% \mathrm{CDW}$ and $10 \% \mathrm{CDW}$ mixtures, decreasing $9 \%$ and $19 \%$, respectively. The other mixtures lost around $23 \%$ of their spreading when compared to their respective initial spreads in the instant $0 \mathrm{~min}$.

At $30 \mathrm{~min}$, the highest flow loss was presented in the $10 \% \mathrm{CDW}$ mixture, which decreased $37 \%$ of the initial flow followed by the REF, $20 \% \mathrm{CDW}$, $15 \% \mathrm{CDW}$ and $5 \% \mathrm{CDW}$ mixtures, which presented a $34 \%, 33 \%, 30 \%$ and $26 \%$ reductions, respectively, when compared to the flow of their own mixtures at 0 min. It is further observed in Figure 2 that the flow loss over time for the $5 \% \mathrm{CDW}$ and $10 \% \mathrm{CDW}$ mixtures showed a better performance when compared to the REF mixture. For the $15 \% \mathrm{CDW}$ and $20 \% \mathrm{CDW}$ mixtures, the loss of spread over time was compatible with the REF mixture. The loss on the slump flow was measured over the time till the mixtures reached a $500 \mathrm{~mm}$ spread. So, at 45 minutes, the $5 \% \mathrm{CDW}$ mixture was the only one that could have its slump flow measured. So, the test had stopped at 30 minutes for REF, $10 \% \mathrm{CDW}$, $15 \% \mathrm{CDW}$ and $20 \% \mathrm{CDW}$ mixtures.

The literature indicates that the SCC-R has a tendency to flow decrease with increasing CDW content when it is used as aggregates, and that this decrease intensifies over the time [21] [34] [35] [36]. This behavior is justified by the high absorption rate of the recycled aggregates [37]. However, although the CDW filler has a high-water absorption due to its porous and rough surface texture [38], the CDW filler also presents a smaller specific surface when compared to the cement used, these factors until the $10 \%$ of CDW filler content had no relevance in terms of fluidity when they replaced the cement (Table 3). As in the course of time the effect of water absorption did not overlap the effect of the chemical reaction of the cement that explains the mixtures containing CDW filler had less 


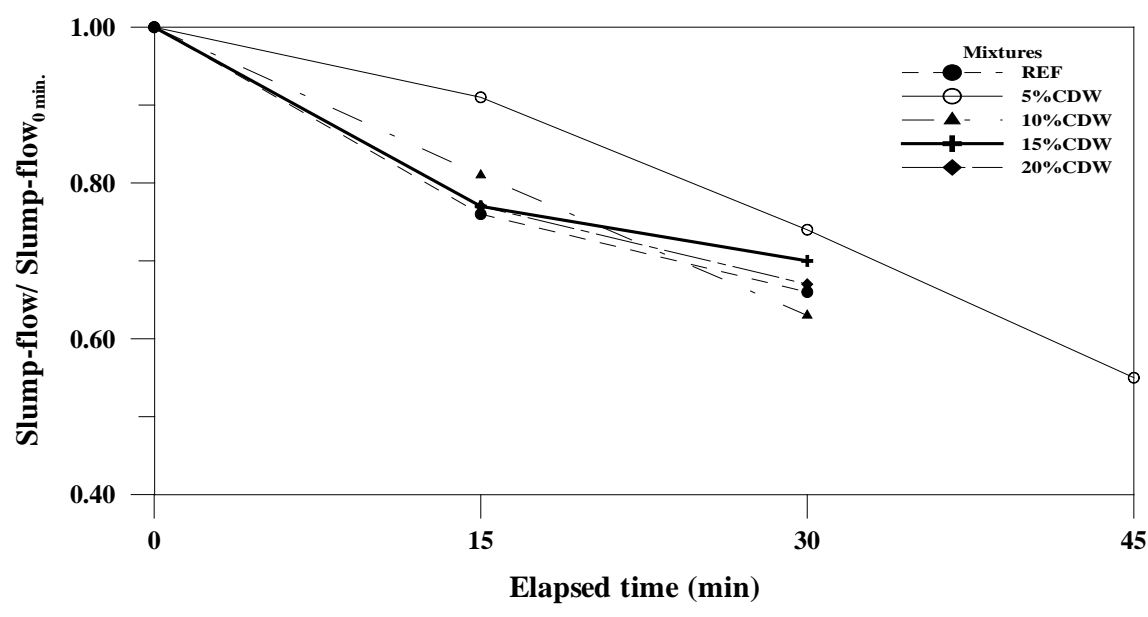

Figure 2. Slump-flow loss over time.

loss of flowability over the time until $15 \mathrm{~min}$. Above 10\% of CDW filler content it is observed that the effect of water absorption is compatible with the effect of the chemical reaction of the cement over time.

By evaluating the apparent plastic viscosity, by means of the t500 test, it is possible to verify that all the mixtures were below the period of 2 seconds, falling within the class VS 1 , for which the SCC is suitable for structural elements with high steel rate, according to NBR 15823-2 [27]. An increase in relative viscosity is also noted with increasing the CDW content.

Analyzing Figure 3, an increase of the apparent viscosity over time is observed. It is also found that the increase in viscosity is greater with the increase of the CDW filler content in the mixture. This behavior was also observed in the studies of Carro-Lopez et al. [34], Tang et al. [36] and González-Taboada et al. [39]. Perius [25] found that the CDW filler was efficient as a viscosity agent, increasing the viscosity of the cementitious matrix. Apparent viscosity loss over time for mixing $15 \% \mathrm{CDW}$ and $20 \% \mathrm{CDW}$, up to 15 minutes, is compatible. However, after 15 minutes, the $20 \% \mathrm{CDW}$ mixture exhibits a different behavior from the $15 \% \mathrm{CDW}$ mixture, not reaching a spreading greater than $500 \mathrm{~mm}$.

In this work, it was also observed that the decrease in fluidity, measured by the flow test, is smaller than the increase in apparent plastic viscosity, measured by the t500 at time 0 (zero) minutes. While the flow test value of mixtures $5 \% \mathrm{CDW}$ and $10 \% \mathrm{CDW}$ remain equal to REF mixture, the mixtures $15 \% \mathrm{CDW}$ and $20 \% \mathrm{CDW}$ show a decrease of only $6 \%$ and $8 \%$ in relation to REF mixture. When it is observed apparent plastic viscosity note that there is an increase of $13 \%, 130 \%, 245 \%$ and $358 \%$ for mixtures $5 \% \mathrm{CDW}, 10 \% \mathrm{CDW}, 15 \% \mathrm{CDW}$ and $20 \% \mathrm{CDW}$, respectively, compared to REF mixture. The literature shows that mixtures with high flow values do not have a relationship between time dependent methods (t500, V-funnel, L-box), nor with flow difference methods (J-ring), locking ratio (L-box) and segregation [40].

By verifying the behavior of the mixtures in the J-ring test, it is noted that all 


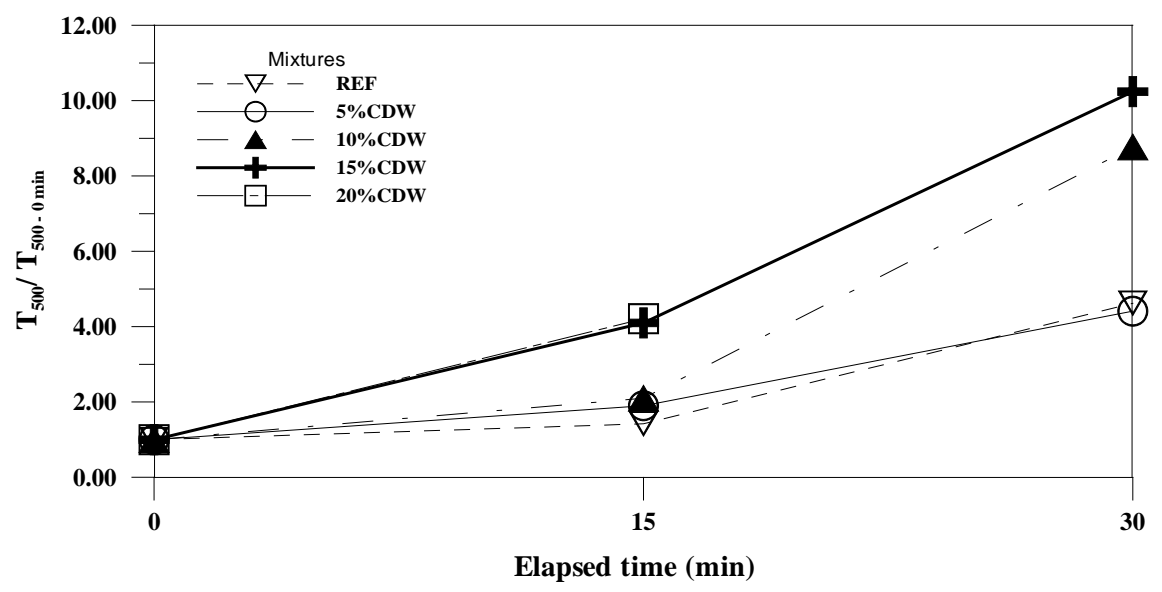

Figure 3. Relative viscosity loss over time.

SCC-Rs were below the maximum limit required per standard, which is at most $50 \mathrm{~mm}$, i.e. all SCC-R mixtures have the ability to flow without causing blockages or losing uniformity, according to NBR 15823-3 [28]. The SCC-R mixtures were classified as PJ 1, which are SCC suitable for structural elements with reinforcement steel spacing from 60 to $80 \mathrm{~mm}$, except for the 10\%CDW mixture, which was rated as PJ 2, which are suitable for structural elements with reinforcement spacing from $80 \mathrm{~mm}$ to $100 \mathrm{~mm}$, according to NBR 15823-3 [28].

In the test performed by the J-ring method, Carro-López et al. [34] observed that the increase in CDW content decreases passing ability. Manzi et al. [41] did not realize the relationship between the passing ability and CDW content, a fact that was also observed in this study because there is no clear trend related to passing ability with increasing CDW content. This can be noted by checking the $10 \% \mathrm{CDW}$ and $20 \% \mathrm{CDW}$ mixtures, which had a spreading difference greater than the difference of the REF and 5\%CDW mixtures. The 15\%CDW mixture did not present differences in the flow and this difference was smaller than the difference of the REF mixtures and 5\%CDW. González-Taboada et al. [39] state that the results obtained by J-ring do not correlate with the results of other empirical parameters.

Evaluating the visual stability index-VSI, during the visual observation in the flow test, it was possible to verify that all SCC-R produced had a homogeneous distribution of the mixture. Thus, they were placed as VSI 0, i.e., there was no evidence of segregation or exudation in the mixture, in conformity with NBR 15823-2 [27], as shown in Figure 4.

Concerning the evaluation of the resistance to segregation by means of the sieve test (Table 3), it was observed that all the SCC-R mixtures were classified as TP2, since the material retained in the sieve was less than or equal to $15 \%$. As well as the passing ability it was also not found in this study a clear trend related to the segregation rate with the variation of the CDW filler content. It was verified that the $5 \% \mathrm{CDW}$ mixture obtained the same segregation rate of the REF mixture and the other mixtures obtained the difference of less than $3 \%, 1 \%$ and 



(a)
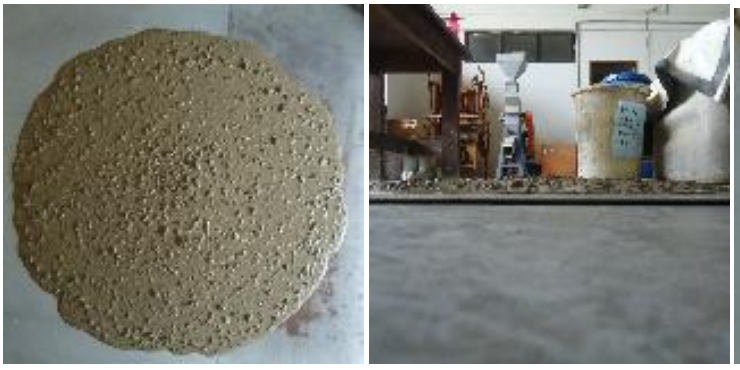

(b)
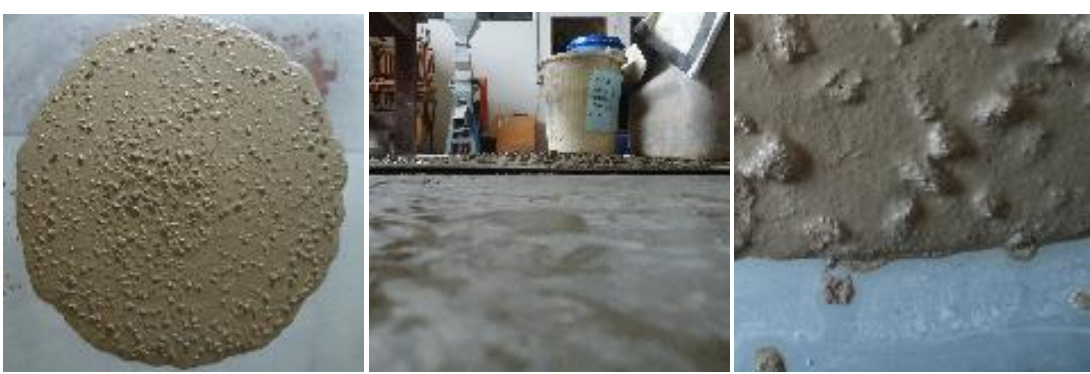

(c)
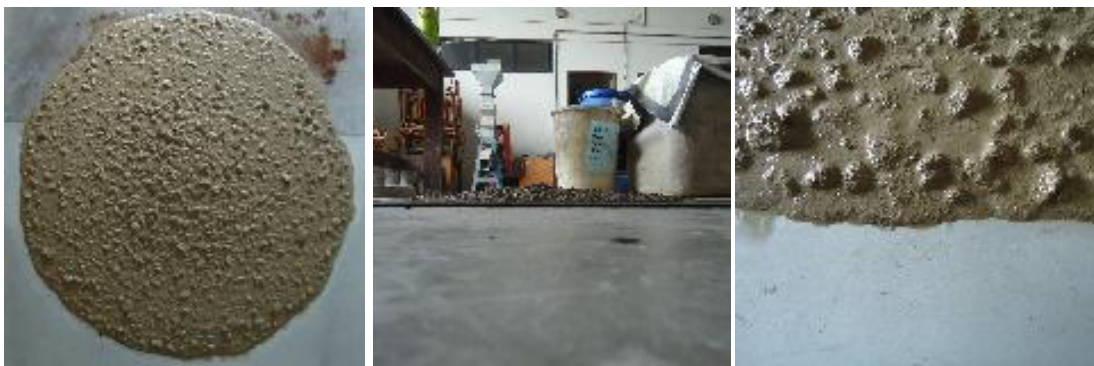

(d)
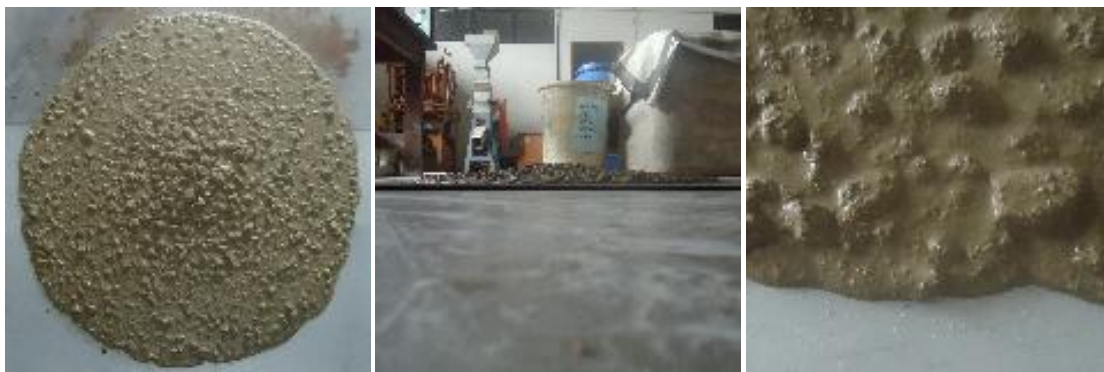

(e)

Figure 4. Fresh visual stability index of SCC-R mixtures: (a) REF; (b) 5\%CDW; (c) $10 \% \mathrm{CDW}$; (d) 15\%CDW; (e) 20\%CDW. 
$7 \%$ for mixtures $10 \% \mathrm{CDW}, 15 \% \mathrm{CDW}$ and $20 \% \mathrm{CDW}$, respectively, when compared to the segregation rate of the REF mixture.

Khayat and De Schutter [42], Tang et al. [36] and González-Taboada et al. [39] also found that the great majority of mixtures of different types of SCC had a segregation rate below 15\%. According to Perius [25], the presence of the CDW filler has a positive influence against segregation when compared to the limestone filler. According to the hypothesis raised by the author, the CDW filler, even though it possesses larger diameter grains than the limestone filler, it has a greater irregularity in the form of its particles, besides the greater porosity of the material, thus helping in the reduction of the possibility of segregation of the SCC mixtures.

As regards the specific gravity in the fresh state, evaluated by the gravimetric method, it was observed that there is a decrease in the results with the increase of the $\mathrm{CDW}$ content in $0.84 \%, 1.37 \%, 2.43 \%$, and $3.17 \%$, for mixtures $5 \% \mathrm{CDW}$, $10 \% \mathrm{CDW}, 15 \% \mathrm{CDW}$ and $20 \% \mathrm{CDW}$, respectively, as compared to the SCC- Ref. This result was expected since the specific gravity of the CDW filler $\left(2.46 \mathrm{~g} / \mathrm{cm}^{3}\right)$ was lower than that of the Portland cement $\left(3.06 \mathrm{~g} / \mathrm{cm}^{3}\right)$ and the increase of the $\mathrm{CDW}$ filler content in the mixture would decrease the specific gravity of the SCC-R.

\subsection{Properties of the SCC-R in the Hardened State}

Table 4 shows the average results of axial compressive strength, splitting tensile strength at 7 and 28 days, absorption rate, void index and specific mass in the hardened state, at 28 days, as well as the standard deviation and coefficient of variation of the studied SCC mixtures.

At 7 days, the compressive strength results of REF, $5 \% \mathrm{CDW}, 10 \% \mathrm{CDW}$, $15 \% \mathrm{CDW}$ and $20 \% \mathrm{CDW}$ mixtures were approximately $91 \%, 76 \%, 77 \%, 79 \%$ and $77 \%$ of the compressive strength at 28 days, respectively. That is, the reference concrete presented the highest initial strength gain. This behavior is due to the type of cement used in the study, high early strength Portland cement, which

Table 4. Hardened properties of SCC-R mixtures.

\begin{tabular}{|c|c|c|c|c|c|c|c|c|c|}
\hline \multirow{2}{*}{ Mixtures } & \multicolumn{2}{|c|}{$\mathrm{fc} \pm \mathrm{Sd}(\mathrm{CV})(\mathrm{MPa})$} & \multicolumn{2}{|c|}{$\mathrm{ft} \pm \mathrm{Sd}(\mathrm{CV})(\mathrm{MPa})$} & \multirow{2}{*}{$\begin{array}{c}\mathrm{A} \pm \mathrm{Sd}(\mathrm{CV}) \\
(\%)\end{array}$} & \multirow[t]{2}{*}{$\begin{array}{c}\mathrm{V} \pm \mathrm{Sd}(\mathrm{CV}) \\
(\%)\end{array}$} & \multicolumn{3}{|c|}{ Density $\pm \mathrm{Sd}(\mathrm{CV})\left(\mathrm{g} / \mathrm{cm}^{3}\right)$} \\
\hline & 7 days & 28 days & 7 days & 28 days & & & $\mathrm{Dd} \pm \mathrm{Sd}(\mathrm{CV})$ & Dsat $\pm S d(C V)$ & $\mathrm{D} \pm \mathrm{Sd}(\mathrm{CV})$ \\
\hline REF & $51.1 \pm 2.0(3.9)$ & $56.4 \pm 1.9(3.4)$ & $4.12 \pm 0.2(6.0)$ & $4.25 \pm 0.1(1.9)$ & $5.6 \pm 0.2(3.1)$ & $12.6 \pm 0.3(2.5)$ & $2.26 \pm 0.01(0.6)$ & $2.39 \pm 0.01(0.4)$ & $2.59 \pm 0.01(0.2)$ \\
\hline $5 \% \mathrm{CDW}$ & $42.9 \pm 1.3(3.1)$ & $56.3 \pm 2.0(3.6)$ & $3.15 \pm 0.1(2.8)$ & $3.35 \pm 0.2(5.6)$ & $5.9 \pm 0.3(4.5)$ & $13.3 \pm 0.5(3.5)$ & $2.24 \pm 0.02(0.9)$ & $2.38 \pm 0.02(0.7)$ & $2.59 \pm 0.01(0.4)$ \\
\hline $15 \% \mathrm{CDW}$ & $42.4 \pm 1.4$ & $53.9 \pm 1.8$ & $3.59 \pm 0.2(5.1)$ & $3.65 \pm 0.2(5.3)$ & $6.9 \pm 0.2(2.4)$ & $14.9 \pm 0.3(1.7)$ & $2.17 \pm 0.02(0.8)$ & $2.32 \pm 0.01(0.6)$ & $2.55 \pm 0.01(0.5)$ \\
\hline $20 \% \mathrm{CDW}$ & $42.0 \pm 1.8$ & $54.4 \pm 0.9$ & $3.53 \pm 0.1(2.4)$ & $3.93 \pm 0.2(4.1)$ & $6.7 \pm 0.3(4.1)$ & $14.6 \pm 0.5(3.4)$ & $2.19 \pm 0.01(0.7)$ & $2.33 \pm 0.01(0.4)$ & $2.56 \pm 0.00(0.2)$ \\
\hline
\end{tabular}


promotes high initial strengths. In addition, in general, the literature indicates that the SCC present greater compressive strength gains at initial ages, such as 3 and 7 days [43] [44]. The mixtures of SCC-R showed lower gains up to 7 days, since the filler, which is an inert material, replaces the Portland cement. Thus, the initial reactivity in these mixtures is less than in the reference mixture. At 7 days, the mixtures containing the CDW filler showed a reduction in the compressive strength results when compared to the average compressive strength of the reference mixture (REF) of about $16 \%$ for $5 \% \mathrm{CDW}$ mixture, $17 \%$ for the $10 \% \mathrm{CDW}$ and $15 \% \mathrm{CDW}$ and $18 \%$ for the $20 \% \mathrm{CDW}$ mixture. In addition, it is important to note that there was no great variation in the average results of compressive strength between the mixtures containing CDW.

At 28 days, it is observed that the average compressive strengths are similar. It is possible to perceive a higher gain of compressive strength with curing time for mixtures containing CDW (approximately 30\%) when compared to the REF mixture (10\%).

In order to confirm if the effects of the influence of the studied variables on the axial compressive strength results were statistically analyzed using the analysis of variance (ANOVA) using Statistica software. The variables verified on the compressive strength were: $\mathrm{CDW}(0-5-10-15-20 \%)$ and age (7 - 28 days). The ANOVA result is shown in Table 5.

The results of ANOVA show that all the studied variables, as well as the interaction between the CDW content and the age have significant effect on the average resistance to the axial compression of the studied mixtures. The CDW content was indicated as the main influence factor in the variation of the mean compressive strength to SCC-R, since it presented the highest calculated F value (368.68). This fact is possibly due to the average compressive strength at 7 days.

As shown in Figure 5, and by performing a multiple comparison analysis of the means of the results using the Tukey test, it was observed that at 7 days there is a significant difference between the average compressive strength for the REF mixture and the other mixtures which use any CDW's content. However, among the average strength results of mixtures containing CDW filler this difference was not observed. At 28 days, it was observed that, for all the mixtures evaluated, there is no difference between the average compressive strengths.

Table 5. Results of ANOVA for compressive strength at 7 and 28 days.

\begin{tabular}{cccccc}
\hline Factors & DF & MS & F & $F_{0.05}$ & Sg \\
\hline CDW filler content & 4 & 33.42 & 13.56 & 2.87 & $\mathrm{~S}$ \\
Age & 1 & 908.63 & 368.68 & 4.35 & $\mathrm{~S}$ \\
CDW filler content - Age & 4 & 16.05 & 6.51 & 2.87 & $\mathrm{~S}$ \\
Error & 20 & 2.46 & & & \\
\hline
\end{tabular}

Note: DF-Degrees of freedom; MS-Mean Square; F-F-distribution; F0.05-F-distribution value at the $5 \%$; Sg—statistical significance; S-statistically significant; NS—statistically not significant. 


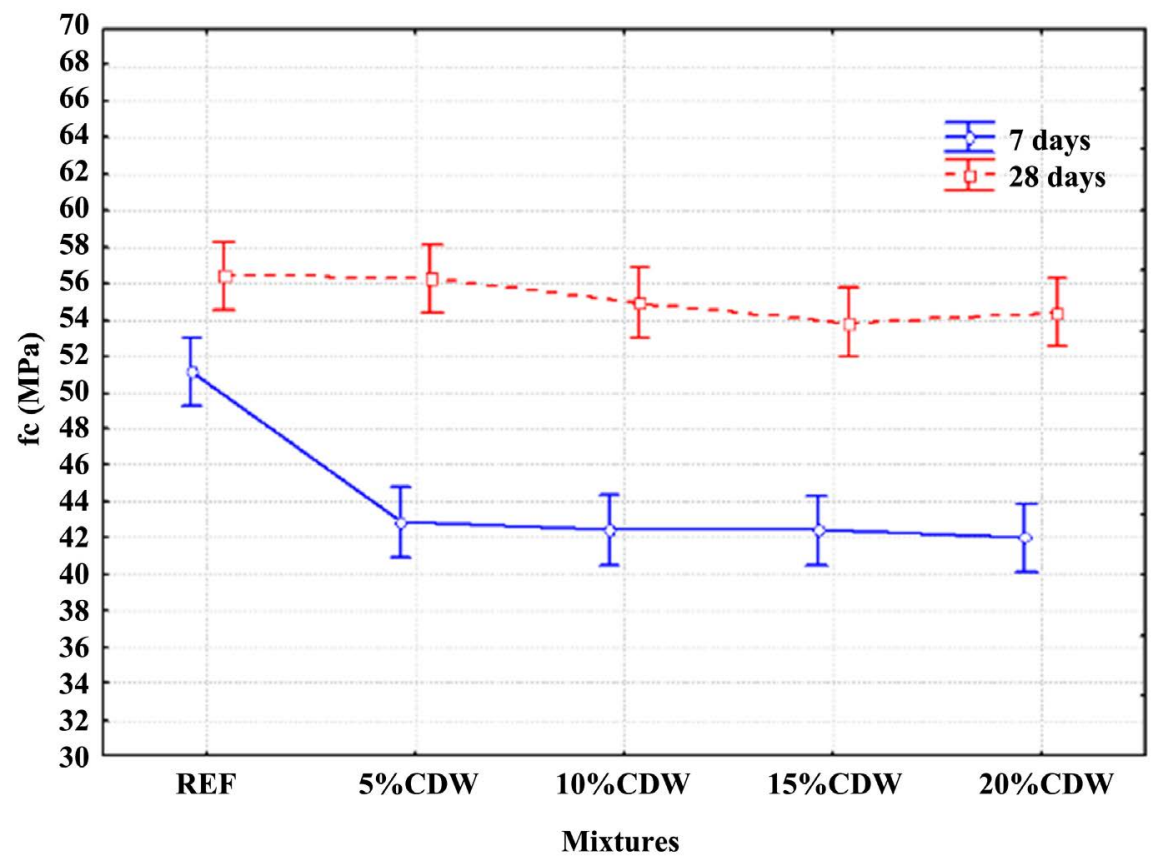

Figure 5. Influence of the studied variables on the mean compressive strength of the SCC-R at 7 and 28 days.

The behavior of higher compressive strengths with increasing curing age was also observed by Silva et al. [45]. In this study the cement was partially replaced by CDW filler from masonry residue from construction and demolition sites. The authors found that the masonry residue affected the compressive strength in the first days of curing, reducing it as the replacement level increased. This behavior was justified by the increase in water/cement ratio, because when the residue replaced the cement, there was no change in the water/binder ratio, resulting in a lower compressive strength. The low reactivity of the masonry residue also affected the compressive strength, because as the cement is replaced in larger quantities and there is less formation of hydration products. These arguments may also explain the behavior of the SCC-R in the early ages of the present study.

A hypothesis for the average compressive strength of the mixtures produced in the present study did not show differences at 28 days, due to the fact that the particles of the CDW filler acted as filler, aiding in the packaging effect and possibly acting as nucleation points of the crystals of $\mathrm{CH}$ (calcium hydroxide) [46]. Another hypothesis may be related to the possible presence of cement (hydrated and non-hydrated) in the CDW fines, which may increase the total amount of cement in the mixture, thus compensating the substituted cement, as was also identified by Katz [47] in his study with CDW's fine aggregate.

Based on the average results of splitting tensile strength at 7 and 28 days, it was observed that the results decreased with an increase of the CDW filler content, both at 7 and 28 days. At 7 days, the average splitting tensile strength of the mixtures studied reached $97 \%, 94 \%, 76 \%, 98 \%$ and $90 \%$ of their tensile strength 
at 28 days for REF mixtures, 5\%CDW, 10\%CDW, 15\%CDW and 20\%CDW, respectively.

At 7 and 28 days, SCC-Ref presented the highest results of mean tensile strength. For 7 days, the average splitting tensile strengths of the SCC containing the CDW filler were lower than the SCC-Ref by about 24\%, 27\%, $13 \%$ and $14 \%$ for the $5 \% \mathrm{CDW}, 10 \% \mathrm{CDW}, 15 \% \mathrm{CDW}$ and $20 \% \mathrm{CDW}$, respectively.

At 28 days, the mixtures $10 \% \mathrm{CDW}$ and $20 \% \mathrm{CDW}$ showed the same average splitting tensile strength. The lowest mean tensile strength was observed for the $5 \% \mathrm{CDW}$ mixture, which showed a reduction of about $21 \%$ in relation to the average splitting tensile strength of the REF mixture. The mixtures 10\%CDW, $15 \% \mathrm{CDW}$ and $20 \% \mathrm{CDW}$ showed reductions of about $7.5 \%, 14.1 \%$ and $7.5 \%$, respectively, compared to the average splitting tensile strength of the REF mixture. The highest mean tensile strength gains were observed for the mixtures $10 \% \mathrm{CDW}(31 \%)$ and 20\%CDW (11\%).

Santos et al. [48] also noticed in the revisions of the studies that deal with SCC with CDW that there is a decrease in the value of the average splitting tensile strengths with the incorporation of this material. Silva et al. [45] observed that at 28 days of curing, the mixtures containing mansory waste residue showed a reduction in average splitting tensile strengths of $1.5 \%$ to $15.3 \%$ when compared to the reference mixture. The authors justify this behavior due to the slowness of the pozzolanic reaction of the residue. However, after 360 days the authors noticed an increase in the average tensile strength compared to the reference mixture up to the replacement content of $37.5 \%$ of masonry residue filler.

It is observed that the relationship between tensile strength and compressive strength at 28 days for all mixtures was less than $10 \%$. As in this study the mixtures are for high strength SCC-R, this behavior was already expected. Although there is a relation between the tensile strength and the compressive strength, the higher the concrete compressive strength, the lower the relation [49].

The analysis of variance (ANOVA) was also performed to verify if there was significant effect of the partial replacement of the cement by the CDW filler and age on the results of average splitting tensile strength. The variables verified on tensile strength were: CDW (0\% - 5\% - 10\% - 15\% - 20\%) and age (7 - 28 days). The ANOVA result is shown in Table 6.

Table 6. Results of ANOVA for splitting tensile strength at 7 and 28 days.

\begin{tabular}{cccccc}
\hline Factors & DF & MS & F & $F_{0.05}$ & Sg \\
\hline CDW filler content & 4 & 0.7339 & 26.70 & 2.87 & $\mathrm{~S}$ \\
Age & 1 & 0.8850 & 32.19 & 4.35 & $\mathrm{~S}$ \\
CDW filler content - Age & 4 & 0.1837 & 6.68 & 2.87 & $\mathrm{~S}$ \\
Error & 20 & 0.0275 & & &
\end{tabular}

Note: DF-Degrees of freedom; MS-Mean Square; F-F-distribution; F0.05-F-distribution VALUE at the 5\%; Sg—statistical significance; S—-statistically significant; NS—statistically not significant. 
By means of the analysis of variance, it was verified that all the studied variables have a significant effect on the splitting tensile strength of the studied mixtures. Age was the most relevant influence factor on the results, since it presented the highest value of calculated F (32.19).

The results were also submitted to a multiple comparison of means, using the Tukey test, which evaluates whether there is a significant difference between the means of the results, and it was observed that:

- At 7 days (as can be noticed in Figure 6), there is a significant difference between the average splitting tensile strength results of the REF mixture relative to all other mixtures containing CDW filler. However, the Tukey test showed that the 5\%CDW mixture showed no significant difference between the mean tensile strength results when compared to $10 \% \mathrm{CDW}, 15 \% \mathrm{CDW}$ and $20 \% \mathrm{CDW}$ mixtures. And for the mixtures $15 \% \mathrm{CDW}$ and $20 \% \mathrm{CDW}$ there was no significant difference between them;

- At 28 days, the REF mixture showed a significant difference between the mean results of tensile strength with the average values of the $5 \% \mathrm{CDW}$ and $15 \% \mathrm{CDW}$ mixtures. The 5\%CDW mixture also showed a significant difference with the $10 \% \mathrm{CDW}$ and $20 \% \mathrm{CDW}$ mixtures, with splitting tensile growth for these mixtures. However, the 10\%CDW and 20\%CDW mixtures showed no significant difference between the mean tensile strength results with the REF mixture or between them, showing that these average results are similar. That is, the use of $10 \%$ and $20 \%$ of CDW filler instead of cement does not promote a decrease in splitting tensile strength.

In what concerns absorption rate and void index, it is observed that, in general,

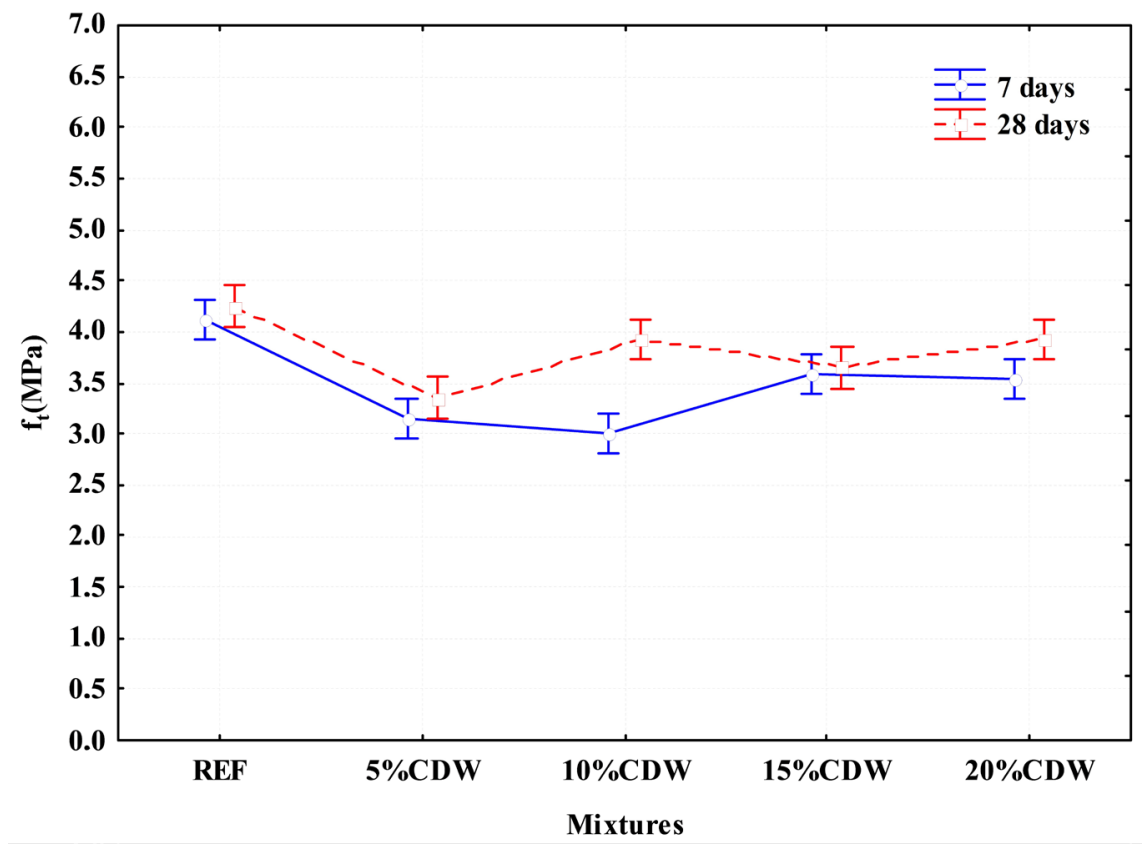

Figure 6. Influence of the variables studied on the average spilitting tensile strength of the SCC-R at 7 and 28 days. 
the value of the water absorption rate and the voids index had similar behaviors: increasing with the increase of the content of CDW up to the mixture 15\%CDW. For the absorption rate, there was an increase of $5.4 \%, 12.5 \%, 23.2 \%$ and $19.6 \%$, while the voids index showed an increase of $5.6 \%, 11.1 \%, 18 \% 2 \%$ and $15.9 \%$ for mixtures of $5 \% \mathrm{CDW}, 10 \% \mathrm{CDW}, 15 \% \mathrm{CDW}$ and $20 \% \mathrm{CDW}$, respectively, when compared to the REF mixture. It is observed that for the $20 \% \mathrm{CDW}$ mixture there is a small decrease in both the water absorption rate and the void index when compared to the $15 \% \mathrm{CDW}$ mixture.

The results of absorption rate and voids index were analyzed statistically (Table 7), through analysis of variance (ANOVA), in which the effect of the variable content of CDW filler on these properties was investigated.

By means of the analysis of variance of the results of the water absorption rate and the voids index it was possible to notice that the CDW content was significant for these properties. There is a small difference in both the water absorption rate and the void index between the REF and 5\% CDW mixtures and between the $15 \% \mathrm{CDW}$ and $20 \% \mathrm{CDW}$ mixtures (Figure 7 (a) and Figure $7(\mathrm{~b})$ ). Therefore, we performed a multiple comparison analysis of the means of the results, using the Tukey's test, and it was observed that the behavior for both the water absorption

Table 7. Results of ANOVA for water absorption and void ratio at 28 days.

\begin{tabular}{ccccccc}
\hline Properties & Factors & DF & MS & F & $F_{0.05}$ & Sg \\
\hline \multirow{2}{*}{ Water absorption rate } & CDW filler content & 4 & 0.8904 & 16.68 & 3.48 & $\mathrm{~S}$ \\
& Error & 10 & 0.0534 & & & \\
\multirow{2}{*}{ Void ratio } & CDW filler content & 4 & 2.761 & 16.13 & 3.48 & $\mathrm{~S}$ \\
& Error & 10 & 0.171 & & & \\
\hline
\end{tabular}

Note: DF-Degrees of freedom; MS-Mean Square; F-F-distribution; F0.05-F-distribution tables at the $5 \%$; Sg-statistical significance; S-statistically significant; NS-statistically not significant.

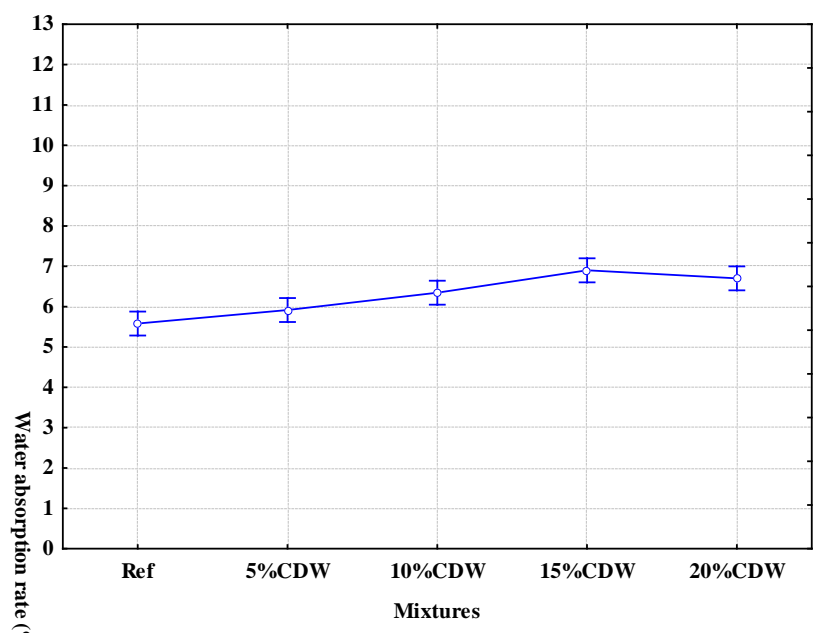

(a)

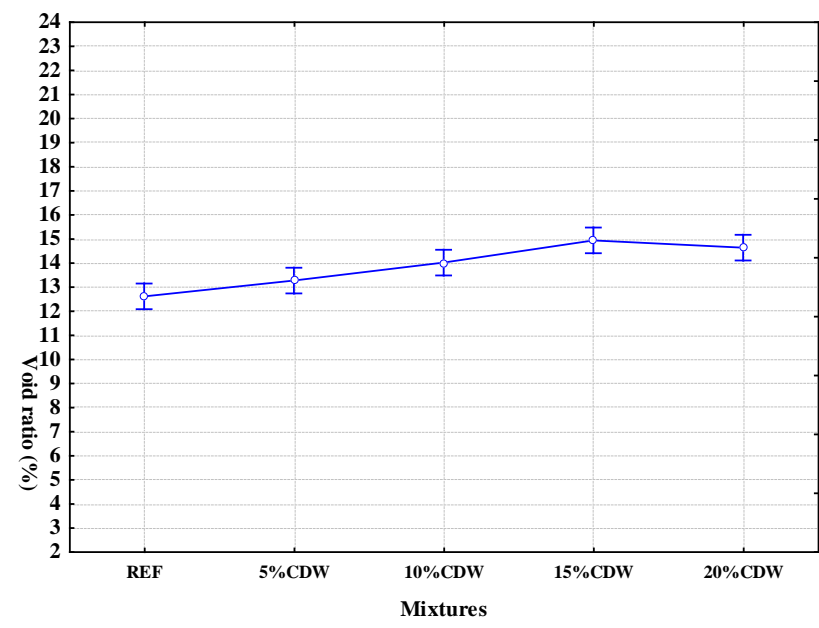

(b)

Figure 7. Influence of the CDW filler content in the studied SCC-R, at 28 days, for the tests: (a) water absorption rate; (b) void ratio. 
rate and the void index is the same: there is no difference of the mean results between the REF and 5\%CDW mixtures, and between the 10\%CDW, 15\%CDW and $20 \% \mathrm{CDW}$ mixtures.

Regarding the results of density, it is noticed that the mixtures present closer values. The REF mixture and the 5\% $\mathrm{CDW}$ mixture obtained similar values of density. There was a decrease of $0.7 \%, 1.6 \%$ and $1.1 \%$ in the density for $10 \%$ $\mathrm{CDW}, 15 \% \mathrm{CDW}$ and $20 \% \mathrm{CDW}$ mixtures, respectively, compared to the REF mixture.

The result of the SCC density was also analyzed statistically (Table 8), through analysis of variance (ANOVA), and the investigated variable was the content of CDW. The results show that the content of CDW has a significant effect on this property.

An analysis of Figure 8 together with a multiple mean comparison analysis using the Tukey's test show that cement substitution by up to $10 \%$ of CDW filler has no significant influence on the density mean value. Furthermore, the mean density results for the $20 \% \mathrm{CDW}$ mixture are statistically equivalent to those of the $10 \% \mathrm{CDW}$ and $15 \% \mathrm{CDW}$ mixtures.

Table 8. Results of ANOVA for density at 28 days.

\begin{tabular}{cccccc}
\hline Factors & DF & MS & F & $\mathrm{F}_{0.05}$ & $\mathrm{Sg}$ \\
\hline CDW filler content & 4 & 0.00099 & 16.00 & 3.48 & $\mathrm{~S}$ \\
Error & 10 & 0.00006 & & & \\
\hline
\end{tabular}

Note: DF-Degrees of freedom; MS-Mean Square; F-F-distribution; F0.05-F-distribution tables at the $5 \%$; Sg—statistical significance; S-statistically significant; NS—statistically not significant.

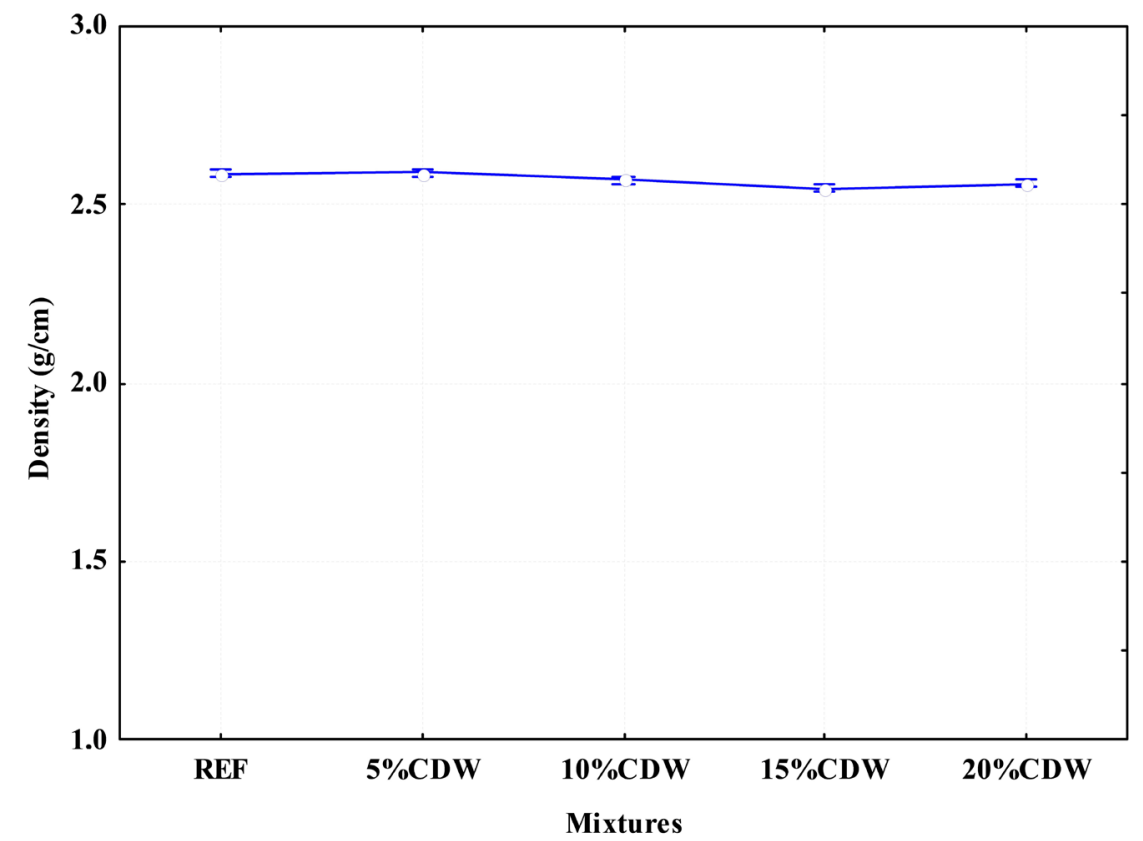

Figure 8. Influence of the CDW filler content on the studied SCC-R, at 28 days, for density. 


\section{Conclusions}

For the self-compacting concrete with CDW filler (SCC-R) evaluated, from the point of view of the mechanical properties and the durability parameters achieved, and considering the compliance with the adopted self-absorption parameters, it is concluded that it is possible to use up to $20 \%$ of CDW filler replacing the Portland cement, maintaining the characteristics of the materials used and the methodologies described. Based on the specific results presented in this study, it was possible to conclude that:

- All the SCC-R properties in the fresh state were met at any substitution level without changing the $\mathrm{w} / \mathrm{c}$ ratio nor superplasticizer content with the increase of CDW filler content. It was possible to verify that the presence of CDW filler, in substitution of Portland cement, improves the resistance to segregation and up to $5 \%$ of CDW filler content decreases the loss of fluidity over time showing that small amounts of CDW filler could promote any changes in the cement hydration mechanism;

- In regard to the properties in the hardened state, it can be observed that the SCC-R mixtures did not meet the mix design approach presented by Gomes [26], which works with a minimum compressive strength of $50 \mathrm{MPa}$ at 7 days. Such behavior possibly happened due to the increase in the w/c ratio (0.42) in the SCC-R mixtures that exceeded the limit of the w/c ratio suggested in that methodology (0.40) and due to the reduction in the consumption of cement with the increase in the CDW filler content, which is a non-reactive mineral addition. Thus, in the future, combining CDW filler with other reactive mineral addition could be tested in order to minimize this effect;

- At 28 days, all mixtures had average compressive strengths above $50 \mathrm{MPa}$, without loss of strength with the increase of up to $20 \%$ of CDW filler in place of Portland cement. With respect to tensile strength, the CDW-containing mixtures achieved results of up to $92.5 \%$ of the reference mixture value. For the water absorption rate and voids index, two durability parameters, CDWcontaining mixtures showed a higher increase of about $23 \%$ and $18 \%$, respectively, relative to the reference mixture values. The highest value of CDW filler content improved both the tensile strength and the porosity of the $20 \% \mathrm{CDW}$ mixture compared to $15 \% \mathrm{CDW}$ showing a promising behavior for the use of higher amounts of the filler from CDW that can be explored for SCC-R production. The density results showed no differences from up to $10 \%$ of CDW filler.

As far as cement consumption is concerned, it is worth noting that there was a reduction of up to $13 \%$ in the cement content by using $20 \%$ of CDW filler. In the case of high performance self-compacting concrete, the reduction of cement consumption without significant interference in the fresh and hardened state properties, especially with respect to the compressive strength, is very important, and maybe higher values of CDW filler contents up to $30 \%$ could be tested in the 
future.

In addition, alternative binary or ternary binder blends, like Portland cement plus CDW filler plus silica fume or metakaolin, should be tested in order to help decreasing the porosity and increasing the mechanical behavior of the SCC-R, since silica fume and metakaolin are considered highly active mineral additions. Also, their highly fine grains with good physical properties could improve the SCC-R packing density and increase the production of hydrated products, such as C-S-H, which can help SCC-R performance.

\section{Acknowledgements}

This study was financed in part by CAPES - Coordenação de Aperfeiçoamento de Pessoal de Nível Superior-Brazil-Finance Code 001, and by FABESB- Fundação de Amparo à Pesquisa do Estado da Bahia [grant number BOL0239/2017].

\section{Conflicts of Interest}

The authors declare no conflicts of interest regarding the publication of this paper.

\section{References}

[1] Oikonomou, N.D. (2005) Recycled Concrete Aggregates. Cement and Concrete Composites, 27, 315-318. https://doi.org/10.1016/j.cemconcomp.2004.02.020

[2] Joseph, P. and Tretsiakova-Mcnally, S. (2010) Sustainable Non-Metallic Building Materials. Sustainability, 2, 400-427. https://doi.org/10.3390/su2020400

[3] ABRELPE Associação Brasileira das Empresas de Limpeza Pública e Resíduos Especiais (2017) Overview of Solid Waste in Brazil in 2016. São Paulo. (In Portuguese)

[4] CONAMA (2002) Ministry of the Environment, National Council for the Environment, CONAMA. CONAMA Resolution No. 307/2002, July 30th. (In Portuguese)

[5] Brazil (2010) Law n ${ }^{\circ}$. 12,305, August 2nd, 2010-National Policy on Solid Waste (PNRS). (In Portuguese)

[6] Etxeberria, M., Marí, A.R. and Vázquez, E. (2007) Recycled Aggregate Concrete as Structural Material. Materials and Structures, 40, 529-541. https://doi.org/10.1617/s11527-006-9161-5

[7] Richardson, A., Allain, P. and Veuille, M. (2010) Concrete with Crushed, Graded and Washed Recycled Construction Demolition Waste as a Coarse Aggregate Replacement. Structural Survey, 2, 142-148. https://doi.org/10.1108/02630801011044244

[8] Leite, M.B., Figueirêdo Filho, J.G. and Lima, P.R.L. (2013) Workability Study of Concretes Made with Recycled Mortar Aggregate. Materials and Structures, 46, 1765-1778. https://doi.org/10.1617/s11527-012-0010-4

[9] Carneiro, J.A., Lima, P.R.L., Leite, M.B. and Toledo Filho, R.D. (2014) Compressive Stress-Strain Behavior of Steel Fiber Reinforced-Recycled Aggregate Concrete. Cement and Concrete Composites, 46, 65-72. https://doi.org/10.1016/j.cemconcomp.2013.11.006

[10] Leite, M.B. and Santana, V.M. (2019) Evaluation of an Experimental Mix Proportion Study and Production of Concrete Using Fine Recycled Aggregate. Journal of 
Building Engineering, 21, 243-253. https://doi.org/10.1016/j.jobe.2018.10.016

[11] Cartuxo, F., de Brito, J., Evangelista, L., Jiménez, J.R. and Ledesma, E.F. (2015) Rheological Behaviour of Concrete Made with Fine Recycled Concrete Aggregates-Influence of the Superplasticizer. Construction and Building Materials, 89, 36-47. https://doi.org/10.1016/j.conbuildmat.2015.03.119

[12] Kumar, R. (2017) Influence of Recycled Coarse Aggregate Derived from Construction and Demolition Waste (CDW) on Abrasion Resistance of Pavement Concrete. Construction and Building Materials, 142, 248-255. https://doi.org/10.1016/j.conbuildmat.2017.03.077

[13] Salesa, A., Pérez-Benedicto, J.A., Esteban, L.M., Vicente-Vas, R. and Orna- Carmona, M. (2017) Physico-Mechanical Properties of Multi-Recycled Self-Compacting Concrete Prepared with Precast Concrete Rejects. Construction and Building Materials, 153, 364-373. https://doi.org/10.1016/j.conbuildmat.2017.07.087

[14] Malta, J.O., Silva, V.S. and Gonçalves, J.P. (2013) Mortar with Recycled Fine Aggregate Derived from Construction and Demolition Waste. Revista Eletrônica de Gestão e Tecnologias Ambientais (GESTA), 1, 176-188. (In Portuguese) https://doi.org/10.17565/gesta.v1i2.7214

[15] Miranda, L.F.R. (2005) Contribution to the Development of the Production and Control of Coating Mortars with Recycled Sand Washed from Waste Class A of the Construction Industry. PhD Thesis, Polytechnic School of University of Sao Paulo, São Paulo.

[16] EFNARC The European Federation for Specialist Construction Chemicals and Concrete Systems (2002) Specification and Guidelines for Self-Compacting Concrete. EFNARC.

[17] ABNT Brazilian Association of Technical Standards (2017) NBR 15823-1: SelfCompacting Concrete-Classification, Control and Reception in the Fresh. Rio de Janeiro. (In Portuguese)

[18] Tutikian, B.F. and Dal Molin, D.C.C. (2015) Self-Compacting Concrete. 2nd Edition, Pini, São Paulo.

[19] Güneyisi, E., Gesoglu, M., Algin, Z. and Yazici, H. (2016) Rheological and Fresh Properties of Self-Compacting Concretes Containing Coarse and Fine Recycled Concrete Aggregates. Construction and Building Materials, 113, 622-630. https://doi.org/10.1016/j.conbuildmat.2016.03.073

[20] Omrane, M., Kenai, S., Kadri, E. and Aït-Mokhtar, A. (2017) Performance and Durability of Self-Compacting Concrete Using Recycled Concrete Aggregates and Natural Pozzolan. Journal of Cleaner Production, 165, 415-430. https://doi.org/10.1016/j.jclepro.2017.07.139

[21] González-Taboada, I., González-Fonteboa, B., Martínez-Abella, F. and Seara-Paz, S. (2018) Thixotropy and Interlayer Bond Strength of Self-Compacting Recycled Concrete. Construction and Building Materials, 161, 479-488. https://doi.org/10.1016/j.conbuildmat.2017.11.157

[22] Singh, N. and Singh, S.P. (2018) Evaluating the Performance of Self-Compacting Concretes Made with Recycled Coarse and Fine Aggregates Using Nondestructive Testing Techniques. Construction and Building Materials, 181, 73-84. https://doi.org/10.1016/j.conbuildmat.2018.06.039

[23] Abed, M., Nemes, R. and Tayeh, B.A. (2020) Properties of Self-Compacting HighStrength Concrete Containing Multiple Use of Recycled Aggregate. Journal of King Saud University_Engineering Sciences, 32, 108-114. 
https://doi.org/10.1016/j.jksues.2018.12.002

[24] Angulo, S.C., Chaves, A.P., John, V.M., Almeida, S.L.M., Lima, F.M.R.S. and Gomes, P.C. (2005) Comparative Analysis of Processing Technology in the Recycling of the Mineral Fraction of Construction and Demolition Waste. Proceedings of XXI ENTMME, Natal, November 2005, 305-312.

[25] Perius, G.R. (2009) Influence of the Physical Properties of Recycled Aggregates on the Retraction by Drying in Self-Compacting Concrete. M.Sc. Thesis, Federal University of Santa Catarina, Florianópolis.

[26] Gomes, P.C.C. (2002) Optimization and Characterization of High-Strength SelfCompacting Concrete. PhD Thesis. Polytechnic University of Catalúnya, Catalúnya.

[27] ABNT Brazilian Association of Technical Standards (2017) NBR 15823-2: SelfCompacting Concrete-Determination of Slump-Flow, Flow Time and Fresh Visual Stability Index-Abrams Cone Method. Rio de Janeiro. (In Portuguese)

[28] ABNT Brazilian Association of Technical Standards (2017) NBR 15823-3: SelfCompacting Concrete-Determination of Passing Abilit-J-Ring. Rio de Janeiro. (In Portuguese)

[29] ABNT Brazilian Association of Technical Standards (2017) NBR 15823-6: SelfCompacting Concrete-Determination of Resistance to Segregation-Method of Segregation Column and Sieve. Rio de Janeiro. (In Portuguese)

[30] ABNT Brazilian Association of Technical Standards (2008) NBR 9833: Fresh Concrete-Determination of Density, Yield and Air Content by Gravimetric Method. Rio de Janeiro. (In Portuguese)

[31] ABNT Brazilian Association of Technical Standards (2007) NBR 5739: Concrete-Compression Test of Cylindric Specimens-Method of Test. Rio de Janeiro. (In Portuguese)

[32] ABNT Brazilian Association of Technical Standards (2011) NBR 7222: Concrete and Mortar-Determination of the Tension Strength by Diametrical Compression of Cylindrical Test Specimens. Rio de Janeiro. (In Portuguese)

[33] ABNT Brazilian Association of Technical Standards (2015) NBR 9778: Hardened Mortar and Concrete-Determination of Water Absorption, Void Index and Density. Rio de Janeiro. (In Portuguese)

[34] Carro-López, D., González-Fonteboa, B., de Brito, J., Martínez-Abella, F., GonzálezTaboada, I. and Silva, P. (2015) Study of the Rheology of Self-Compacting Concrete with Fine Recycled Concrete Aggregates. Construction and Building Materials, 96, 491-501. https://doi.org/10.1016/j.conbuildmat.2015.08.091

[35] Kebaili, O., Mouret, M., Arabi, N. and Cassagnabere, F. (2015) Adverse Effect of the Mass Substitution of Natural Aggregates by Air-Dried Recycled Concrete Aggregates on the Self-Compacting Ability of Concrete: Evidence and Analysis through an Example. Journal of Cleaner Production, 87, 752-761. https://doi.org/10.1016/j.jclepro.2014.10.077

[36] Tang, W.C., Ryan, P.C., Cui, H.Z. and Liao, W. (2016) Properties of Self- Compacting Concrete with Recycled Coarse Aggregate. Advances in Materials Science and Engineering, 2016, Article ID: 2761294. https://doi.org/10.1155/2016/2761294

[37] Silva, R.V., de Brito, J. and Dhir, R.K. (2018) Fresh-State Performance of Recycled Aggregate Concrete: A Review. Construction and Building Materials, 178, 19-31. https://doi.org/10.1016/j.conbuildmat.2018.05.149

[38] Ferreira, R.L.S., Anjos, M.A.S., Pereira, J.E.S., Fonseca, N.J.M. and Nóbrega, A.K.C. 
(2019) Evaluation of the Physical, Chemical and Mineralogical Properties of the Fine Fraction $(<150 \mu \mathrm{m})$ of the Recycled CDW Aggregate. Cerâmica, 65, 139-146. https://doi.org/10.1590/0366-69132019653732453

[39] González-Taboada, I., González-Fonteboa, B., Eiras-López, J. and Rojo-López, G. (2017) Tools for the Study of Self-Compacting Recycled Concrete Fresh Behaviour: Workability and Rheology. Journal of Cleaner Production 156, 1-18. https://doi.org/10.1016/j.jclepro.2017.04.045

[40] Khayat, K.H. and Mitchell, D. (2008) Research Description and Findings to SelfConsolidating Concrete for Precast, Prestressed Concrete Bridge Elements. Final Report for NCHRP Project, 18-12. https://doi.org/10.17226/14188

[41] Manzi, S., Mazzotti, C. and Bignozzi, M.C. (2017) Self-Compacting Concrete with Recycled Concrete Aggregate: Study of the Long-Term Properties. Construction and Building Materials, 157, 582-590.

https://doi.org/10.1016/j.conbuildmat.2017.09.129

[42] Khayat, K. and De Schutter, G. (2014) Mechanical Properties of Self-Compacting Concrete State-of-the-Art Report of the RILEM Technical Committee 228-MPS on Mechanical Properties of Self-Compacting Concrete. Springer, London.

https://doi.org/10.1007/978-3-319-03245-0

[43] Panda, K.C. and Bal, P.K. (2013) Properties of Self-Compacting Concrete Using Recycled Coarse Aggregate. Procedia Engineering, 51, 159-164. https://doi.org/10.1016/j.proeng.2013.01.023

[44] Vinay Kumar, B.M., Ananthan, H. and Balaji, K.V.A (2017) Experimental Studies on Utilization of Coarse and Finer Fractions of Recycled Concrete Aggregates in Self Compacting Concrete Mixes. Journal of Building Engineering, 9, 100-108. https://doi.org/10.1016/j.jobe.2016.11.013

[45] Silva, Y.F., Lange, D.A. and Delvasto, S. (2019) Effect of Incorporation of Masonry Residue on the Properties of Self-Compacting Concretes. Construction and Building Materials, 196, 277-283. https://doi.org/10.1016/j.conbuildmat.2018.11.132

[46] Felekoglu, B. (2007) Utilization of High Volumes of Limestone Quarry Wastes in Concrete Industry (Self-Compacting Concrete Case). Resources, Conservation and Recycling, 51, 770-791. https://doi.org/10.1016/j.resconrec.2006.12.004

[47] Katz, A. (2003) Properties of Concrete Made with Recycled Aggregate from Partially Hydrated Old Concrete. Cement and Concrete Research, 33, 703-711. https://doi.org/10.1016/S0008-8846(02)01033-5

[48] Santos, S., da Silva, P.R. and de Brito, J. (2019) Self-Compacting Concrete with Recycled Aggregates-A Literature Review. Journal of Building Engineering, 22, 349371. https://doi.org/10.1016/j.jobe.2019.01.001

[49] Akinpelu, M.A., Odeyemi, S.O., Olafusi, O.S. and Muhammed, F.Z. (2019) Evaluation of Splitting Tensile and Compressive Strength Relationship of Self-Compacting Concrete. Journal of King Saud University_Engineering Sciences, 31, 19-25. https://doi.org/10.1016/j.jksues.2017.01.002 